Kansas State University Libraries

New Prairie Press

\title{
MODELING THE ROOT-KNOT NEMATODE/NUTSEDGE PEST COMPLEX: PERSPECTIVES FROM WEED SCIENCE, NEMATOLOGY AND STATISTICS
}

\author{
Leigh Murray \\ Stephen H. Thomas \\ Jill Schroeder \\ Scott Kreider \\ Zhining Ou
}

See next page for additional authors

Follow this and additional works at: https://newprairiepress.org/agstatconference

Part of the Agriculture Commons, and the Applied Statistics Commons

\section{(c) (1) $9 \odot$}

This work is licensed under a Creative Commons Attribution-Noncommercial-No Derivative Works 4.0 License.

\section{Recommended Citation}

Murray, Leigh; Thomas, Stephen H.; Schroeder, Jill; Kreider, Scott; Ou, Zhining; Trojan, J. M.; and Fiore, C. (2011). "MODELING THE ROOT-KNOT NEMATODE/NUTSEDGE PEST COMPLEX: PERSPECTIVES FROM WEED SCIENCE, NEMATOLOGY AND STATISTICS," Conference on Applied Statistics in Agriculture. https://doi.org/10.4148/2475-7772.1051

This is brought to you for free and open access by the Conferences at New Prairie Press. It has been accepted for inclusion in Conference on Applied Statistics in Agriculture by an authorized administrator of New Prairie Press. For more information, please contact cads@k-state.edu. 


\section{Author Information}

Leigh Murray, Stephen H. Thomas, Jill Schroeder, Scott Kreider, Zhining Ou, J. M. Trojan, and C. Fiore 


\title{
MODELING THE ROOT-KNOT NEMATODE/NUTSEDGE PEST COMPLEX: PERSPECTIVES FROM WEED SCIENCE, NEMATOLOGY AND STATISTICS
}

\author{
Leigh Murray ${ }^{1}$, Stephen H. Thomas ${ }^{2}$, Jill Schroeder ${ }^{2}$, Scott Kreider $^{3}$, Zhining $\mathrm{Ou}^{1}$, J. M. Trojan ${ }^{2}$ \\ and C. Fiore ${ }^{2}$ \\ ${ }^{1}$ Department of Statistics, Kansas State University, Manhattan, KS 66506; ${ }^{2}$ Department of \\ Entomology, Plant Pathology and Weed Science, New Mexico State University, Las Cruces, NM \\ 88003; ${ }^{3}$ Craig Hospital, Denver, CO. Corresponding author's email: lmurray@ksu.edu.
}

\begin{abstract}
Previous research by the authors has established that southern root-knot nematode (SRKN, Meloidogyne incognita (Kofoid \& White) Chitwood) and yellow and purple nutsedge (YNS, Cyperus esculentus L. and PNS, C. rotundus L.) form a pest-complex that adversely affects a wide variety of crops in the southern and western U.S. These pests appear to have co-evolved a mutually-beneficial relationship that promotes the survival of both nematodes and weeds to the detriment of crops. Traditional management has usually targeted one pest at a time, but managing this pest complex requires that all members of the complex be managed simultaneously. A series of experiments was performed to determine if this specific pest complex could be managed through crop-rotation using a non-dormant $M$. incognita-resistant variety of alfalfa (Medicago sativa) which can aggressively compete with, and hence decrease, occurrence of both species of nutsedges (NS), and subsequently decrease SRKN by decreasing the availability of root systems of host plants. A previous journal article discussed predicting counts of SRKN second-stage juveniles (SRKN-J2) as a function of YNS and PNS plant counts from a two-year alfalfa rotation experiment, using the Poisson distribution and a scale parameter to handle problems of overdispersion. In this paper, we examine three generalizations of the Poisson distribution that allow for the count variance being larger than the mean count: the Generalized Poisson, the Zero-Inflated Poisson (ZIP), and the Poisson Hurdle. The ZIP and Hurdle Poisson distributions both account for zero counts as a separate part of the distribution, while the Generalized Poisson incorporates a separate parameter that increases the variance relative to the mean. Different biological scenarios are presented for which each of these three general Poisson distributions might be logically appropriate. In addition, we use the alfalfa rotation data to present comparisons of fitted regression models of the three general Poisson distributions to the results from the previous analysis using the Poisson. For this data, there was no single probability distribution that worked best for all six sampling dates (three in each of the two years). This is not surprising in that over time the alfalfa rotation was, as planned, decreasing both nutsedge and nematode counts, thus presenting a "moving target" for the modeling process.
\end{abstract}

Keywords: Nematodes; Nutsedge; Poisson; Generalized Poisson; Zero-Inflated Poisson; Poisson Hurdle; Overdispersion 


\section{Introduction}

\subsection{Overview of the Southern Root-Nematode/Nutsedge Pest Complex}

Southern root-knot nematode (SRKN, Meloidogyne incognita (Kofoid \& White) Chitwood), yellow nutsedge (YNS, Cyperus esculentus L.), and purple nutsedge (PNS, Cyperus rotundus L.) occur simultaneously in many crops grown throughout the southern and western regions of the United States. These three pests have worldwide distribution in cultivated tropical and semitropical regions and are major pests of most cultivated crops. In many specialtycropping regions, broad-spectrum fumigants have been used to suppress these pests; however, the continued availability of these fumigants (methyl bromide and its replacements) is in question. New Mexico producers have not used these fumigants to any great extent; therefore, the increasing prevalence of difficult-to-control perennial weeds in fields infested with SRKN triggered an interdisciplinary research project aimed at determining the nature of this emerging problem.

Yellow nutsedge and PNS are creeping perennial weeds common throughout the irrigated regions of the Southwest (Lee 1991) and the world (Holm et al. 1991). Purple nutsedge is more common in the thermal belt of the world because growth is limited by cold temperatures and low moisture conditions. Yellow nutsedge tolerates colder temperatures and drier conditions than does PNS and is found in much of North America, as far north as Canada and Alaska (Bendixen and Nandihalli 1987). Nutsedges (NS) are most competitive with crops that have a limited canopy or are not aggressive competitors (Keeley 1987). Competitive crops decrease growth and tuber production because both nutsedge species are sensitive to shading and desiccation (Keeley 1987, Stoller and Sweet 1987). However, effective weed control practices have exacerbated the nutsedge problem in many crops because other weeds are removed and a lack of management alternatives for nutsedge species allows these weeds to occupy the remaining niche. Good fertility management can enable the crop to successfully compete with nutsedge if the crop has a vigorous growth habit; however, with noncompetitive crops (such as many vegetables), the nutsedges tend to be more competitive under high fertility practices. When left undisturbed, both YNS and PNS can produce thousands of tubers in a growing season (Stoller and Sweet 1987). These tubers are the source of new infestations the following year. Management practices that are limited to cultivation or hand-removal of nutsedge plants show limited success in controlling YNS and PNS because the practices do not kill the tubers. Few herbicides are effective in controlling these weeds; however, a combination of these practices along with rotation to competitive crops provides effective suppression of these weeds (Fiore et al. 2009).

Root-knot nematodes are world-wide in distribution and the most economically important genus of plant-parasitic nematodes. Among them, SRKN is the predominant species and has the widest geographic distribution ( $40^{\circ} \mathrm{N}$ latitude to $33^{\circ} \mathrm{S}$ latitude) and host range (Eisenback and Triantaphyllou 1991), parasitizing more than 2,000 plant species, including a wide range of crops and weeds (Bendixen 1988). Southern root-knot nematodes are sedentary endoparasites that spend nearly all of their life submerged in plant roots where they induce functional changes in certain cells upon which they feed. Once inside roots, all developmental stages of SRKN are protected from nematicides and undetectable through standard nematode soil 
sampling procedures (Nyczepir and Thomas 2009). Only recently-hatched pre-parasitic second stage juveniles (SRKN-J2) are detectable in soil prior to host invasion. (Note that in the following, the "SRKN" is used as a general abbreviation but that "SRKN-J2" refers specifically to the second stage juveniles, counts of which are the response variable modeled in this research). Generation time for the parasite is 25 days, with each adult female producing approximately 500 progeny, leading to enormous populations over the growing season. Damage from SRKN delays or prevents crop canopy closure, resulting in greater weed proliferation, and manifests as yield reductions that often exceed 40\% in susceptible crops (Lindsey and Clayschulte 1982, Thomas et al. 1995). Management of SRKN depends primarily on preplant treatment of soil with fumigant or nonfumigant nematicides, or the use of crop cultivars with resistance to the parasite (Nyczepir and Thomas 2009). General availability of nematicides for many crops is dwindling due to environmental concerns, their use substantially increases crop production costs, and these products are ineffective when nutsedge tubers are present to harbor and protect SRKN.

Research (Bird and Hogger 1973, Hogger and Bird 1976, Schroeder et al. 1993, 1994, 2004, 2005, Thomas et al. 1997, 2004, 2005) identified relationships between SRKN and common weed species, particularly YNS and PNS, that occur simultaneously in sandy soils used to produce chile pepper (Capsicum annuum L., hereafter referred to as 'chile') and most rotational crops. Yellow nutsedge, PNS and SRKN do not disseminate readily and, unlike their damaging effects on crops, are well-adapted to a mutually-beneficial coexistence that sustains and enhances the pest complex. Both nutsedge species were determined to be good hosts for SRKN, and SRKN infection increased the number and size of nutsedge tubers (Schroeder et al. $1999,2004)$ the primary propagative units of these weeds. Nutsedge tubers harbor southern rootknot nematode(Thomas et al. 2004), protecting the nematodes from fumigant nematicides and deleterious environmental conditions. Therefore, early emergence of nutsedges in the spring may accelerate the production of the first generation of nematodes, and nutsedges can affect the virulence of SRKN to subsequent crops (Thomas et al. 1997). The resurgence of nematodes from within the tuber increased nematode populations two to three months sooner than what would be expected after fumigation by the nematicide 1,3-dichloropropene (1,3-D) (Schroeder et al. 2007).

The negative impact of the pest complex on the efficacy of cultural or chemical management practices that target either nutsedges or SRKN alone, reinforce the necessity of addressing the entire complex simultaneously. This need is exacerbated by the phase-out of methyl bromide uses and limits in utility of replacement fumigants to serve as general biocides. To be effective, cultural options must suppress the entire pest complex. The use of rotational cropping systems is one potential cultural practice to control such a pest complex. Issues to consider in identifying suitable rotational crops include: first, persistence of herbicides used in these crops may lead to unacceptable carryover injury to successive crops; and second the potential rotational crop must be resistant to the SRKN but effectively competitive with the nutsedges, and finally be acceptable to producers in terms of economics and water availability. The use of a nondormant, SRKN-resistant alfalfa, which has aggressive growth and can compete with nutsedge for light and other resources, can provide simultaneous suppression of all three pests and is an economical rotation option for New Mexico chile growers (Fiore et al. 2009). 
Research conducted from 1997-2003 evaluated a three-year planting of SRKN-resistant alfalfa, compared to cotton as a rotation crop, for suppression of the pest complex. The alfalfa rotation allowed the successful production of a chile crop without requiring the application of 1,3-D for SRKN suppression after terminating the alfalfa. However, the pest complex resurged to levels similar to 1997 by the end of the growing season in 2003. This result showed that an integrated approach to limit resurgence of the pest complex is needed for sustainable crop production.

A two-year study was initiated in September 2004 to determine if a two-year rotation of SRKN-resistant alfalfa followed by targeted herbicide treatment in the chile pepper crop slowed resurgence of the pest complex (Ou et al. 2008). Given the beneficial relationships between nutsedges and SRKN as well as the need to be able to determine if the pest complex was effectively suppressed by the alfalfa crop, work was also needed to determine whether the location of the nutsedge populations in an alfalfa crop rotation could predict field locations where greater SRKN-J2 counts occur in the soil and where nematode resurgence might initiate in subsequent crops. Therefore, the following hypothesis was addressed by Ou et al. (2008): YNS and/or PNS plant counts in an alfalfa field infested with the SRKN/NS pest complex could be used as a predictor of SRKN-J2 populations. The specific objective of the work was to evaluate polynomial regression models to predict the number of SRKN-J2 in soil samples as a function of YNS and PNS counts and their squares and cross-product. Counts of SRKN-J2 at the time of alfalfa establishment averaged $63 / 100 \mathrm{~cm}^{3}$ soil, which is about 25 times the damage threshold for chile (Thomas et al. 1995) and is considered a heavy infestation. Yellow and purple nutsedge populations were dense and evenly distributed throughout the experimental field. The alfalfa stand was managed for two years from September 2004 through October 2006 according to production practices common in the Rio Grande valley (I. M. Ray, NMSU, pers. com.) of southern New Mexico. Although such alfalfa fields are typically maintained for at least three years, previous research suggested that suppression of the SRKN/NS pest complex occurred by the end of the second growing season (Fiore et al. 2009). Therefore, two years in the alfalfa rotation were considered sufficient to address the experimental objective.

A 55- $\times 100$-m section of the 1 ha alfalfa field was chosen for intensive data collection, based on previous experience with irrigation and crop uniformity. This section was partitioned into a grid with a total number of 1,375 plots of size 2- $\times 2-\mathrm{m}$, and was sampled in May, July, and September in both 2005 and 2006. The goal of this sampling strategy was to determine both the density and distribution of the three pest species during the alfalfa rotation. The soil samples were paired with the nutsedge plants (when present) to determine whether the nutsedge and nematode populations were associated in the field. At each sample date, eighty $2-\times 2-\mathrm{m}$ plots were randomly selected out of the 1,375 plots. No plots were sampled twice in a year. Data at each sample date included YNS and PNS counts and SRKN-J2 counts recovered from soil. Nematode populations were estimated by compositing and extracting ten $50 \mathrm{~cm}^{3}$ soil cores collected near nutsedge plants, if present, or at random if no nutsedge plants were present. 


\subsection{Previous Modeling of Southern Root-Knot Nematode Counts as a Function of Nutsedge Counts using the Poisson Distribution.}

Previous modeling (Ou et al. 2008) of SRKN J2 counts from the two-year alfalfa rotation study was done with the Poisson probability distribution function ( $p d f$ ) and log link function using the GENMOD procedure in SAS ${ }^{\circledR}$ (version 9.1; SAS Institute, 2008). Models were fitted separately for the six sample dates, using YNS and PNS counts, their squares and the cross-product term as possible predictors of SRKN-J2 counts. Specific model results will be discussed in Section 4 below.

Poisson models for all six dates showed some overdispersion (McCullagh and Nelder 1989, Littell et al. 2006) with Deviance/d.f. values ranging from 1.2 to 2.1. Overdispersion in one-parameter distributions like the Poisson occurs when the variability of the data is larger than the theoretical variance of the distribution being used, which results in parameter estimates having standard errors that are "too small" and hence confidence intervals that are too narrow and tests of significance that have inflated Type 1 error rates. More specifically, in the case of the Poisson, the variability of the observed counts was larger than the Poisson parameter which is both the Poisson mean and variance.

Overdispersion with this data was not surprising for two reasons. First, the field being used had a long history of heavy SRKN infestation, which resulted in large SRKN-J2 counts at the beginning of the experiment (May 2005). Second, over time, the alfalfa crop decreased NS counts and subsequently SRKN-J2 counts (as intended), resulting in larger numbers of zero counts. Both circumstances therefore produced overdispersion, albeit for different reasons.

To solve the overdispersion problem, Ou et al. (2008) used "rescaling" (McCullagh and Nelder 1989), which imposes a multiplicative overdispersion factor, so that the variance of the counts ( $\mathbf{r})$ becomes

$$
\operatorname{Var}(Y)=\lambda \phi \quad,
$$

where $\phi>1$ is the scale parameter. The scale parameter can be estimated by either

$$
\hat{\phi}=\sqrt{\text { Deviance/d.f. }}
$$

or

$$
\hat{\phi}=\sqrt{\text { Pearson's } \chi^{2} / \text { d.f. }}
$$

(McCullagh and Nelder 1989, Littell et al. 2006). With this method, point estimates of model parameters and predicted values (both on log=model scale and count=data scale) don't change, but standard errors become larger and hence confidence intervals are wider and the Type 1 error rate decreases (McCullagh and Nelder 1989, Littell et al. 2006). However, a drawback of this method is that one no longer has a $p d f$ (Schabenberger and Stroup 2008) in a strict sense, since the absolute relation between the Poisson mean and variance has been relaxed. Rather, one has a quasi-likelihood function (Wedderburn 1974). On the other hand, this approach has high 
efficiency if the overdispersion is small (Cox 1983). Ou et al. (2008) used the Deviance form to estimate the overdispersion scale parameter (McCullagh and Nelder 1989).

Another solution is to use a $p d f$ other than the Poisson. Traditionally the Negative Binomial has been used for count data as an alternative to the Poisson (Young and Young 1998) but recently two-parameter extensions of the Poisson have been developed and their use is explored in this paper, in terms of both conceptual biological scenarios and of results of modeling SRKN-J2 counts from the two-year alfalfa rotation experiment.

\section{Three Two-parameter Generalizations of the Poisson to Handle Overdispersion}

Three generalizations of the Poisson are considered: the Generalized Poisson (GzP; Consul 1989, Joe and Zhu 2005), the Zero-Inflated Poisson (ZIP; Simonoff, 2003), and the Poisson Hurdle model (PH; Grogger and Carson 1991, Welsh et al. 1996). The pdf, mean and variance for counts $Y=0,1,2,3 \ldots$ are summarized in Table 1 for the Poisson and its three generalizations, plus the condition under which each generalization reduces to the Poisson. In the following comparison between the Poisson and the three generalizations, we ignore the effect of modeling predictors and use the notation $P_{P}(Y=y), P_{G z P}(Y=y), P_{Z I P}(Y=y)$, and $P_{P H}(Y=y)$ to denote probabilities associated with the Poisson, GzP, ZIP and PH distributions, respectively.

The GzP incorporates an extra parameter $<$ that increases of the mean of the GzP relative to the Poisson but increases the variance even more. Note that, like the Poisson, the GzP does not treat zeros separately, as the other two generalizations do. Comparing the Poisson probabilities with those of the GzP, we see that the Poisson and GzP distributions have the same probability of a zero count, that is,

$$
P_{G l P}(Y=0)=P_{P}(Y=0)=\exp (-\lambda)
$$

For counts $Y>0$, there is a boundary value $y^{*}$ such that for $1 \leq Y \leq y^{*}$, the Poisson probability is greater than the respective GzP probability and for $Y>y^{*}$, the Poisson probability is less than that of the GzP. For example, for the parameter combination $\lambda=2$ and $\xi=.5$, the boundary value is $y^{*}=3$ and so the Poisson probability is greater than the respective GzP probability for $Y=1,2,3$, but is less for $Y \geq 4$. In comparison, for $\lambda=10$ and $\xi=.5$, the boundary value is $y^{*}=14$. Therefore, the GzP is like a Poisson with a long upper tail and is useful in modeling overdispersion caused by "large" counts relative to the Poisson.

In contrast, the ZIP and PH distributions model zeros separately but in slightly different ways. In the ZIP distribution, zero counts arise from two sources, a Bernoulli process (with parameter $\pi_{c}$ ) and a Poisson process (with parameter - ). For zero counts, the ZIP probability is inflated over that of the corresponding Poisson, that is,

$$
P_{Z I P}(Y=0)=\pi_{0}+\left(1-\pi_{0}\right) P_{P}(Y=0)>P_{P}(Y=0) \quad,
$$

while for counts greater than zero, the ZIP probability is lower than that of the Poisson, that is,

$$
P_{Z I P}(Y=y)=\left(1-\pi_{0}\right) P_{P}(Y=y)<P_{P}(Y=y) \quad \text { for } Y>0 \text {. }
$$


For the PH distribution, zero counts arise from a single Bernoulli process (with parameter $\pi_{H}$ ). When modeling the zero-inflated case, $\pi_{H}$ is greater than the zero-count probability of the Poisson, that is,

$$
P_{P H}(Y=0)=\pi_{H}>\exp (-\lambda)=P_{P}(Y=0)
$$

Then for counts greater than 0 , the $\mathrm{PH}$ probability is lower than that of the Poisson, that is,

$$
P_{P H}(Y=y)=P_{P}(Y=y) \times C<P_{P}(Y=y) \quad \text {, for } Y>0,
$$

where

$$
C=\frac{1-\pi_{H}}{1-\exp (-\lambda)}<1 .
$$

Although not common, the PH distribution can also be used in cases of deflated zeros, with

$$
\pi_{H}<\exp (-\lambda)
$$

SAS ${ }^{\circledR}$ code (version 9.2; SAS Institute, 2010) was obtained from Schabenberger and Stroup (2008) for GzP (GLIMMIX procedure), ZIP (GENMOD and NLMIXED procedures) and PH (NLMIXED) $p d f$ s.

In terms of choosing an appropriate $p d f$, statistical criteria are typically used, such as AIC or other information criteria for goodness of fit (GOF), Pearson's or Deviance $\chi$ `for dispersion diagnosis, and/or significance of predictors. In the next section, we take a different tack and discuss what $p d f$ s make sense in terms of the nematode/nutsedge pest complex in agroecosystems.

\section{Possible Biological Scenarios for the Nematode/Nutsedge Pest Complex in Agro- ecosystems, as Related to the Poisson Family of Distributions}

There are several factors that may impact the SRKN/NS pest complex in agroecosystems. First, for purposes of discussion here, we will consider the case where YNS and PNS are the only weed hosts present and occur in patches of various sizes (area and plant counts). Second, crops can be either hosts (e.g., chile pepper, cotton, onions) or non-hosts (e.g., the nematode-resistant variety of alfalfa). The third factor is soil texture: nematodes will not be found in heavy clay soils, but will be found in well-drained sandy soils. Another factor is that of water application and drainage. Nematode juveniles and eggs can be spread along a drainage gradient when a field is subjected to flood irrigation. In contrast, center-pivot irrigation systems or dryland cropping systems (where rainfall is the only source of water) typically do not produce as much lateral water movement. Finally, the spatial distribution of the nematode infestation may be that of a few small patches with low SRKN-J2 counts (e.g., a recent SRKN infestation), more and larger SRKN patches with higher counts (hotspots that develop following initial lowcount contamination), or an almost uniform spatial distribution with low, medium and high counts (longstanding infestation). Recall that YNS, PNS, and SRKN do not disseminate readily; however, contamination of new sites can occur through movement of soil from infested to noninfested fields by numerous sources including farm implements, labor crews, migratory birds, and grazing livestock. 
The first scenario (Figure 1) is a situation where a field is mostly sandy soil but has one or more clay lenses. Also, the crop is not a host for SRKN and the nematode infestation is recent enough that not all NS patches contain SRKN. In this case, the Zero-Inflated Poisson model may be appropriate as there are two possible reasons for zero counts of SRKN-J2: the effect of the clay lens which is modeled by the Bernoulli ( $\pi_{j}$ ) part of the $p d f$, and the Poisson part of the probability of zero SRKN-J2 counts (i.e., $\left(1-\pi_{0}\right) P_{P}(Y=0)$ ) which arises from the fact that not all NS patches are infested with SRKN. A related scenario (Figure 2) occurs when, again, clay regions are present in a field that is flood-irrigated. However, in this case the field is planted with a host crop, and the SRKN infestation is of long enough duration that the crop and weed patches are generally infested to some extent. Here the vast majority of zero SRKN-J2 counts will occur because of clay soils, so the Poisson Hurdle model may be more appropriate than the ZIP, with all zero counts being accounted for by the Bernoulli parameter $\pi_{\boldsymbol{t}}$.

The remaining two scenarios assume a uniform sandy soil. Figure 3 represents either a very recent SRKN contamination or a SRKN infestation that has been effectively controlled in a field with either flood or center-pivot irrigation and with both NS and a crop serving as SRKN hosts. As shown in Figure 3, the very low incidence of SRKN results in a few small SRKN patches with relatively small SRKN-J2 counts. These SRKN patches are tied to both crop and NS plants. The Poisson with a small - (e.g., $\lambda \leq 3$ ) may fit this situation, as there will be a large number of zero SRKN-J2 counts but these will not result in overdispersion because the rest of the SRKN-J2 counts are still small. Differences in method of watering will not make much difference as nematodes have been suppressed by the previous non-host crop or there hasn't been sufficient time for SRKN to move far from the point of contamination. However, in a situation where contamination is of long-standing and only susceptible crops have been grown, differences in water application may make a big difference in the SRKN spatial pattern.

Figure 4 represents a long-standing SRKN contamination in a field with center-pivot irrigation where both NS and crop serve as SRKN hosts. Watering in a center-pivot irrigation system will not move SRKN very far. Instead, SRKN will be spread by tuber growth from infested NS plants, so that there will be a pattern of circular SRKN/NS hotspots of very high SRKN-J2 counts. In this case, the Generalized Poisson may be an appropriate model because it can more easily accommodate large counts than the other $p d f \mathrm{~s}$. In the case where flood irrigation is being used, SRKN/NS "hotspots" will likely develop in a linear fashion along the irrigation gradient from sites of contamination (scenario not shown). In this case, spatial coordinates that account for irrigation direction might be used as either fixed or random effects in the modeling process. The Generalized Poisson might still be expected to work in this case.

The two-year alfalfa rotation modeled in Ou et al. (2008) was somewhat different from the four scenarios presented above. The field was flood-irrigated and had a uniform sandy soil and a long-established SRKN/NS presence such that the entire field was heavily infested with both the nematodes and nutsedges at the beginning of the rotation study. Recall that the management objective was to use the non-SRKN host variety of alfalfa to decrease NS and hence SRKN over time. The statistical objective in Ou et al. (2008) was to determine if YNS and PNS plant counts could be used to estimate SRKN-J2 counts in the soil at each sampling 
date using the Poisson distribution. The next section presents the results from the current modeling of that data.

\section{Current Modeling of SRKN-J2 Counts using the Generalized Poisson, Zero-Inflated Poisson and Poisson Hurdle}

As in Ou et al. (2008), models were fitted separately for the six sampling dates, using YNS and PNS counts, their squares and the cross-product term as possible predictors, and using the GzP, ZIP and PH pdfs. Regression models were fitted for the Poisson parameter - for all $p d f$ s and for the Bernoulli parameter $\neg$ for both the ZIP and PH. Nutsedge predictors were not significant for $\tau$. for either ZIP or PH on any date, so results are not shown. Previous results (Ou et al.2008) for the Poisson and the Poisson using the Deviance rescaling method ("Poisson/Dscale" for short) are included here for ease of comparison. Summaries of fitted models are presented in Table 2 (May 2005), Table 3 (Sep 2006), Table 4 (July 2005), Table 5 (Sep 2005), Table 6 (May 2006) and Table 7 (July 2006). Model results are not presented in chronological order, but in sets of dates that displayed similar predictor models.

\subsection{Dates with only PNS as a Predictor.}

Models for May 2005 and Sep 2006 had PNS as the only significant predictor for Poisson and Poisson/Dscale (Ou et al. 2008). For May 2005, PNS was likewise the only significant predictor for GzP, ZIP and PH (Table 2). Regression coefficient estimates and their standard errors were very similar between the Poisson, Poisson/Dscale and GzP on one hand and between the ZIP and PH on the other. Likewise, point estimates of mean SRKN-J2 counts as well as their confidence intervals (CIs) were very similar between the Poisson, Poisson/Dscale and GzP. Point estimates of means for the ZIP were overall lower than those for Poisson, Poisson/Dscale and Gzp, with narrower CIs as well, especially for values of PNS over 1. Point estimates were lower and CIs narrower for the PH than for the ZIP. Although statistically significant, the zeroinflation probabilities for ZIP and PH were not very high (.18 \pm .06 vs $.26 \pm .05$, respectively). The GzP had the lowest AIC (304), making it the "best" choice for May 2005 based on AIC. Results for other information criteria were similar to AIC.

With regard to considering the biological processes that generated the May 2005 data, it does perhaps make sense that the GzP may be the best $p d f$. As noted above, this field has a fairly uniform sandy soil as well as a long-established NS and SRKN presence across the field. In this case, there were NS and SRKN hotspots that had developed over years of cultivation and experimentation. The overdispersion problem in this case would result from moderate to large SRKN-J2 counts, not from large numbers of zero counts. This possible scenario is represented in Figure 5.

For Sep 2006, PNS was the one significant predictor for Poisson, Poisson/Dscale and GzP and like May 2005 models, Poisson, Poisson/Dscale and Gzp were very similar with respect to regression coefficient estimates and standard errors, and estimated mean SRKN-J2 counts and confidence intervals. In comparison, intercept and PNS coefficient estimates were not significant for ZIP and PH. Instead, the Bernoulli part of these $p d f$ s dominated with high zeroinflation probabilities of $.65 \pm .10$ for ZIP and $.78 \pm .05$ for PH. The results for ZIP and PH are 
consistent with the biological process of decreasing the SRKN's NS host over two years of alfalfa growth. As with May 2005 results, estimated mean SRKN-J2 counts and CIs were very similar for Poisson, Poisson/Dscale and GzP, with ZIP results again being lower (except at PNS $=0$ ) and $\mathrm{PH}$ being lowest. This pattern held even though the fitted models looked quite different between the Poisson, Poisson/Dscale and GzP on one hand and the ZIP and PH on the other. As hoped for, estimated mean SRKN-J2 counts were much lower than equivalent estimates from May 2005, at the beginning of the alfalfa rotation. However, estimated mean SRKN-J2 counts obtained from all $p d f$ s were at or above the .24 SRKN-J2/10cc soil which is the economic threshold for chile pepper (Ou et al. 2008, Thomas et al. 1995). This indicates the need for at least one more year of alfalfa production before switching to a sensitive crop like chile.

Unlike with May 2005, where GzP was clearly the best of the three alternative pdfs in terms of AIC, AIC was not able to distinguish among GzP, ZIP, and PH, which had AICs ranging from 130.8 to 132.8. AICs for these three were certainly much lower than for the Poisson (AIC=142), but that is not much consolation in trying to pick the best alternative to the Poisson. Pearson's $\chi^{\bar{z}}$ did indicate that GzP was better than ZIP but was not available for the $\mathrm{PH}$, which was fitted in the SAS NLMIXED procedure.

We hypothesize that by Sep 2006, the mutually-beneficial relationship between SRKN and its NS hosts that is seen under more typical agronomic conditions may have fallen apart due to NS plants being under extreme stress from shading by the alfalfa. This scenario is represented in Figure 6. A similar pattern was seen in another experiment (data not shown) that looked at the pest complex under fertilizer stress. In such cases, NS may not be a good predictor of SRKN-J2 counts.

\subsection{Dates with YNS, PNS and the YNS $x$ PNS Cross-product as Predictors.}

Models for July and Sep 2005 (Tables 4, 5) had YNS, PNS and YNSxPNS as significant predictors for the Poisson (Ou et al. 2008), with both YNS and PNS having positive coefficients and being significant at $c=0.05$ and with the cross-product having a negative coefficient and being significant at $c=0.10$. When rescaling was done via Poisson/Dscale, for both dates the cross-product became not significant at $c=0.10$ and the PNS coefficient became significant only at $c=0.10$. This had suggested that the cross-product term being significant in both dates was a fluke and that YNS was more important than PNS as a predictor in the middle and end of the first growing season (Ou et al. 2008).

This earlier conclusion was reinforced for July 2005 models using GzP and ZIP (Table 4) with YNS being the only predictor significant at $c=.05$. In comparison, the PH model found none of the predictors significant, but did have a high zero-inflation probability (.49 \pm .06 ). The reason for this inconsistency is not known. Estimated mean SRKN-J2 counts showed similar patterns to that of May 2005 and Sep 2006, with Poisson, Poisson/Dscale and GzP being similar in point estimates and CIs, ZIP being lower in general and PH being lowest. As with Sep 2006

models, AIC did not distinguish between GzP, ZIP or PH, or even Poisson. Pearson's $\chi^{2}$ did again indicate that GzP was better than ZIP. 
In contrast, for Sep 2005 data using GzP, ZIP and PH (Table 5), ZIP and PH models did have regression models with highly significant YNS, PNS and YNSxPNS terms $(p<0.01)$ with coefficients being positive for YNS and PNS and negative for YNSxPNS. In addition, both ZIP and $\mathrm{PH}$ had highly significant high zero-inflation probabilities $(.41 \pm .08$ and $.58 \pm .06$, respectively). Estimated mean SRKN-J2 counts tended to be similar for Poisson, Poisson/Dscale and GzP, but ZIP values were sometimes lower than those three and sometimes higher. Estimated mean SRKN-J2 counts for PH were again consistently the lowest. AIC indicated that the PH model was the "best."

A potential reason for the sometimes significant cross-product term may lie in competition between YNS and PNS which needs to be explored in further work.

\subsection{Dates with No NS Predictors.}

Models for May and July 2006 (Tables 6, 7) had no significant NS predictors for the Poisson and Poisson/Dscale (Ou et al. 2008), so intercept-only models were fitted. Models using the GzP, ZIP and PH were also intercept-only. For both May and July 2006, intercept point estimates were identical between the Poisson, Poisson/Dscale and GzP, with of course larger standard errors for Poisson/Dscale and GzP. Both ZIP and PH models had nonsignificant intercepts but highly significant high zero-inflation probabilities. This is similar to the July 2005 PH model. Again reinforcing the idea that models with different forms can produce similar estimated means, the estimated mean SRKN-J2 counts were identical between the Poisson, Poisson/Dscale, GzP and ZIP, with differences only in CIs for both dates. In comparison, the PH had a lower estimated mean, again in both dates. The GzP model had slightly lower AIC and

lower Pearson's $\chi^{\bar{z}}$ in May 2006 but in July 2006 only the Pearson's $\chi{ }^{\bar{c}}$ indicated that GzP was better in fit.

For May and July 2006, we hypothesize that the typical mutually-beneficial relationship between SRKN and its NS hosts was not working in the early to middle of the growing season of the second year of the alfalfa rotation, due to alfalfa shading out both NS species and thus reducing SRKN hosts. The fact that a relationship was found in Sep 2006 between PNS and SRKN-J2 counts may indicate that PNS was able to grow better than YNS at the end of the 2006 growing season.

\section{Summary}

Previous research has demonstrated that southern root-knot nematodes (SRKN) and yellow nutsedge (YNS) or purple nutsedge (PNS) form a mutually beneficial pest complex in irrigated, sandy soils of the southwest. The pests must be managed together and research has demonstrated that an integrated management strategy incorporating both SRKN host and nonhost crops may be sustainable. In order to determine the effectiveness of an integrated management strategy, SRKN populations must be estimated regularly. However, SRKN populations are difficult and expensive to sample due to the fact that nematodes are a soilborne organism and spatially non-uniform. Because of the SRKN association with nutsedges, we 
hypothesized that YNS and/or PNS plant counts in a field infested with the SRKN/NS pest complex could be used as a predictor of SRKN populations. We asked the following questions relating the biology of this pest complex to statistical modeling:

1. Can YNS and/or PNS counts be used to estimate the SRKN-J2 counts in soil? The answer to this question was yes; however, the appropriate Poisson distribution varied depending on the time of year and nutsedge numbers.

2. Can we use the field/crop/etc situation to decide what pdf might be appropriate (never mind the statistics)? The answer to this question was yes but the situation is a moving target. As field conditions changed, the appropriate $p d f$ changed. The intensive management of the system successfully suppressed the pest complex; therefore, the biological situation that we were modeling changed over time. In a less dynamic agronomic situation, the SRKN/NS pest complex might be well-modeled by a single $p d f$, depending on the particular biological scenario.

With respect to future modeling of the alfalfa rotation data, the next step is to try to incorporate spatial information, in the form of $(\mathrm{x}, \mathrm{y})$ coordinates for each quadrat, into models as either fixed predictors to account for possible hotspots that are linear in the direction of irrigation flow or as random effects to account for spatial variability.

Future work is needed to validate the principles outlined in this manuscript. The models need to be tested under varying field conditions such as different field environments (soil type changes within a field, different irrigation schemes), under different cropping systems (host crop versus non-host crop), and under different densities of SRKN, YNS, and PNS. This presents an opportunity to develop collaborative efforts with scientists in other locations.

\section{References}

Bendixen, L. E. (1988) A comparative summary of the weed hosts of Heterodera, Meloidogyne, and Pratylenchus nematodes. Special Circular 118. Wooster, OH: Ohio State University Ohio Agricultural Research and Development Center.

Bendixen, L. E. and Nandihalli, U. B. (1987) Worldwide distribution of purple and yellow nutsedge (Cyperus rotundus and C. esculentus). Weed Technology 1: 61-65.

Bird, G. W. and Hogger, C. H. (1973) Nutsedges as hosts of plant-parasitic nematodes in Georgia cotton fields. Plant Disease Reporter 57:402.

Consul, P. C. (1989) Generalized Poisson Distributions - Properties and Applications. New York City, NY: Marcel Dekker, Inc.

Cox, D. R. (1983) Some remarks on overdispersion. Biometrika 70: 269-274.

Eisenback, J. D. and Triantaphyllou, H. H. (1991) Root-knot nematodes: Meloidogyne species and races. Pp. 191-274 in W. R. Nickle, ed. Manual of Agricultural Helminthology. New York, NY: Marcel Dekker Inc.

Fiore, C., Schroeder, J., Thomas, S., Murray, L., and Ray, I. (2009) Root-knot nematoderesistant alfalfa suppresses subsequent crop damage for the nutsedge-nematode pest complex. Agronomy Journal 101:754-762.

Grogger, J.T. and Carson, R.T., (1991) Models for truncated counts. Journal of Applied Econometrics, 6(2): 225-238. 
Hogger, C. H. and Bird , G. W. (1976) Weed and indicator hosts of plant-parasitic nematodes in Georgia cotton and soybean fields. Plant Disease Reporter 60:223-226.

Holm, L. G., Plucknett , D. L., Pancho J. V., and Herberger, J. P. (1991) The World's Worst Weeds, Distribution and Biology. Krieger Publishing Co., Malabar, FL. 609 pp.

Joe, H, and Zhu, R. (2005) Generalized poisson distribution: the property of mixture of poisson and comparison with negative binomial distribution. Biometrical Journal 47 (2): 219229.

Keeley, P. E. (1987) Interference and interaction of purple and yellow nutsedges (Cyperus rotundus and C. esculentus) with crops. Weed Technology 1:74-81.

Lee, R. (1991) Weeds End Report. New Mexico State Univ., Coop. Ext. Serv., U.S. Dep. Agric. New Mexico Crop Pest Reporter. Vol. 9, No. 13. December, 1991.

Lindsey, D. L. and Clayshulte, M. S. (1982) Influence of initial population densities of Meloidogyne incognita on three chile cultivars. Journal of Nematology 14:353-358.

Littell, R. C., Milliken, G. A., Stroup, W. W., Wolfinger, R. D., and Schabenberger, O. (2006) SAS for Mixed Models $2^{\text {nd }}$ edition. Cary, NC: SAS Institute, Inc.

McCullagh, P. and Nelder, J. A. (1989) Generalized Linear Models $2^{\text {nd }}$ edition. New York City, NY: Chapman and Hall.

Nyczepir, A. P. and Thomas, S. H. (2009) Current and future management strategies in intensive crop production systems. Pp. 412-443 in R. N. Perry, M. Moens and J. L. Starr, eds. Root-knot Nematodes. Wallingford, UK: CAB International.

Ou, Z., Murray, L., Thomas, S. H., Schroeder, J., and Libbin, J. (2008) Nutsedge counts predict Meloidogyne incognita juvenile counts in an integrated management system. Journal of Nematology, 40(2): 99-108.

SAS Institute, Inc. (2008) SAS OnlineDoc® Version 9.1.3. Cary, NC: SAS Institute Inc. SAS Institute, Inc. (2010) SAS OnlineDoc® Version 9.2. Cary, NC: SAS Institute, Inc.

Schabenberger, O. and Stroup, W. W. (2008) Generalized Linear Mixed Models: Theory and Applications [PowerPoint slides]. Joint Statistical Meetings - Continuing Education Two-Day Course CE 01 C, Denver, CO, 2-3 ${ }^{\text {rd }}$ August 2008.

Schroeder, J., Kenney, M., Thomas , S. H., and Murray , L. (1994) Yellow nutsedge response to southern root-knot nematodes, chile peppers, and metolachlor. Weed Science 42:534540.

Schroeder, J., Nunez, S. C., Thomas, S. H., and Murray, L. W. (2007) Early season irrigation affects initial development of yellow nutsedge, purple nutsedge, and root-knot nematode. Western Society of Weed Science Proceedings 60:39.

Schroeder, J., Thomas S. H., and Murray, L. (1993) Yellow and purple nutsedge and chile peppers host southern root-knot nematode. Weed Science 41:150-156.

Schroeder, J., Thomas, S. H., and Murray, L. (1999) Yellow (Cyperus esculentus) and purple nutsedge (Cyperus rotundus) are not injured by increasing root-knot nematode (Meloidogyne incognita) population density. Weed Science 47:201-207.

Schroeder, J., Thomas, S. H. and Murray, L. (1999) Yellow (Cyperus esculentus) and purple nutsedge (Cyperus rotundus) are not injured by increasing root-knot nematode (Meloidogyne incognita) population density. Weed Science 47:201-207. 
Schroeder, J., Thomas, S. H., and Murray, L. W. (2004) Root-knot nematodes affect annual and perennial weed interactions with chile pepper. Weed Science 52:28-46.

Schroeder, J., Thomas , S. H., and Murray, L. (2005) Impacts of crop pests, and their management, on weeds. Weed Science 53:918-922.

Simonoff, J. S. (2003) Analyzing Categorical Data. New York City, NY: Springer-Verlag New York, Inc.

Stoller, E. W. and Sweet , R. D. (1987) Biology and life cycle of purple and yellow nutsedges (Cyperus rotundus and C. esculentus). Weed Technology 1:66-73.

Thomas, S. H., Murray, L. and Cardenas, M. (1995) Relationship of preplant population densities to root-knot nematode damage thresholds for three chile pepper cultivars. Plant Disease 79:557-559.

Thomas, S. H., Schroeder, J., Kenney, M. J., and Murray, L.W. (1997) Meloidogyne incognita inoculum source affects host suitability and growth of yellow nutsedge and chile pepper. Journal of Nematology 29:404-410.

Thomas, S. H., Schroeder, J., and Murray, L.W. (2004) Cyperus tubers protect Meloidogyne incognita from 1,3-dichloropropene. Journal of Nematology 36:131-136.

Thomas, S. H., Schroeder, J. and Murray, L. (2005) The role of weeds in nematode management. Weed Science 53:923-928

Wedderburn, W.M. (1974) Quasi-likelihood functions, generalized linear models, and the GaussNewton method. Biometrika 61:439-447.

Welsh, A. H., Cunningham, R.B., Donnelly, C.F., and Lindenmayer, D.B., (1996). Modelling the abundance of rare species: statistical models for counts with extra zeros. Ecological Modelling, 88(1): 298-308.

Young, L.J. and Young, G. H. (1998) Statistical Ecology: A Population Perspective. Boston: Kluwer Academic. 
Table 1. A comparison of the probability mass functions and moments for the Poisson, Generalized Poisson, Zero-Inflated Poisson and Poisson Hurdle

\begin{tabular}{|c|c|c|c|c|}
\hline & Poisson & Generalized Poisson & Zero-Inflated Poisson & Poisson Hurdle \\
\hline $\begin{array}{l}P D F \\
\text { and } \\
\text { Parameter } \\
\text { Space }\end{array}$ & $\begin{array}{l}\operatorname{Pr}(Y=j) \\
=\frac{\lambda^{j} \exp (-\lambda)}{j !}, \\
j=0,1,2,3, \ldots\end{array}$ & $\begin{array}{l}\operatorname{Pr}(Y=j) \\
=\frac{\lambda(\lambda+\xi j)^{j-1} \exp (-\lambda-\xi j)}{j !} \\
j=0,1,2,3, \ldots \\
\text { for } \lambda>0,0 \leq \xi<1 \text {, and } \\
\xi=1-1 / \exp (\phi) \quad, \text { where } \\
\quad \leq \text { is the usual scale parameter }\end{array}$ & 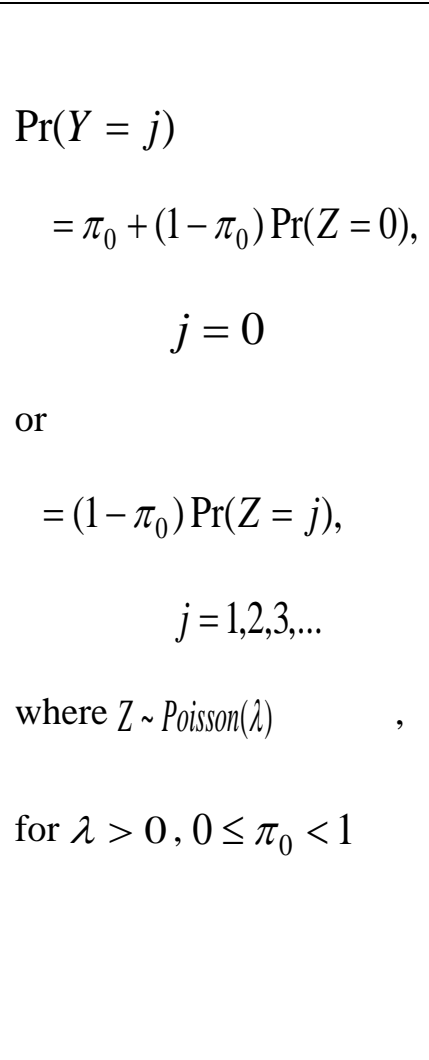 & $\begin{array}{l}\operatorname{Pr}(Y=j) \\
\quad=\pi_{H}, \\
\qquad j=0 \\
\text { or } \\
\quad=\frac{\left(1-\pi_{H}\right) \operatorname{Pr}(Z=j)}{[1-\operatorname{Pr}(Z=0)]} \\
\qquad j=1,2,3, \ldots \\
\text { where } Z \sim \operatorname{Poisson}(\lambda) \quad, \text { for } \lambda>0, \\
0 \leq \pi_{H}<1\end{array}$ \\
\hline$E(Y)$ & $E(Y)=\lambda$ & $E(Y)=\lambda /(1-\xi)$ & $E(Y)=\lambda\left(1-\pi_{0}\right)=\mu_{0}$ & $E(Y)=\lambda\left(1-\pi_{H}\right) /[1-\exp (-\lambda)]$ \\
\hline$V(Y)$ & $V(Y)=\lambda$ & $V(Y)=\lambda /(1-\xi)^{3}$ & $V(Y)=\lambda\left(1-\pi_{0}\right)\left(1+\lambda \pi_{0}\right)$ & $V(Y)=\mu_{H}(1+\lambda)-\mu_{H}^{2}$ \\
\hline Poisson if & & $\xi=0$ & $\pi_{0}=0$ & $\pi_{H}=\exp (-\lambda)$ \\
\hline
\end{tabular}


Table 2. Results for May 2005 data for Southern root knot nematode (SRKN) J2 counts (response) as a function of the predictor purple nutsedge counts (P) using the probability models: Poisson ${ }^{\mathrm{a}}$, Poisson with Dscale correction, Generalized Poisson, Zero-Inflated Poisson and Poisson Hurdle $(n=80)$.

\begin{tabular}{|c|c|c|c|c|c|}
\hline Results & Poisson & $\begin{array}{l}\text { Poisson with } \\
\text { Dscale }\end{array}$ & $\begin{array}{c}\text { Generalized } \\
\text { Poisson }\end{array}$ & $\begin{array}{l}\text { Zero-Inflated } \\
\text { Poisson }\end{array}$ & $\begin{array}{l}\text { Poisson } \\
\text { Hurdle }\end{array}$ \\
\hline Pearson's $\chi^{2}$ & 176.8 & 176.8 & 81.18 & 124.1 & - \\
\hline d.f. & 78 & 78 & 80 & 77 & - \\
\hline$\chi^{2} / d . f$. & 2.27 & 2.27 & 1.01 & 1.61 & - \\
\hline AIC & 329.6 & 329.6 & 304.2 & 321.3 & 322.2 \\
\hline \multicolumn{6}{|l|}{$\begin{array}{l}\text { Poisson Mu } \\
\text { Model Beta } \\
\text { Estimates } \pm \text { s.e. }^{\text {b }}\end{array}$} \\
\hline$\hat{\beta}_{0} \pm$ s.e. & $.59 \pm .09$ & $.59 \pm .13$ & $.57 \pm .13$ & $.80 \pm .10$ & $.81 \pm .10$ \\
\hline $\mathrm{p}$-value & $\mathrm{p}<0.0001$ & $\mathrm{p}<0.0001$ & $\mathrm{p}<0.0001$ & $\mathrm{p}<0.0001$ & $\mathrm{p}<0.0001$ \\
\hline$\hat{\beta}_{P} \pm$ s.e. & $.51 \pm .12$ & $.51 \pm .18$ & $.51 \pm .18$ & $.42 \pm .13$ & $.40 \pm .13$ \\
\hline p-value & $\mathrm{p}<0.0001$ & $p=0.0054$ & $p=0.0065$ & $p=0.0018$ & $\mathrm{p}=0.0028$ \\
\hline \multicolumn{6}{|l|}{ Scale Estimate } \\
\hline$\hat{\phi} \pm$ s.e. & $-{ }^{c}$ & 1.46 & $.39 \pm .10$ & - & - \\
\hline$\hat{\xi}=1-1 / \exp (\hat{\phi})$ & - & - & .32 & - & - \\
\hline \multicolumn{6}{|l|}{$\begin{array}{l}\text { Inflation } \\
\text { Parameter } \\
\text { Estimates }\end{array}$} \\
\hline$\hat{\alpha}_{0} \pm$ s.e. & - & - & - & $-1.53 \pm .40$ & $-1.03 \pm .25$ \\
\hline p-value & - & - & - & $\mathrm{p}=0.0018$ & $\mathrm{p}=0.0001$ \\
\hline$\hat{\pi} \pm$ s.e. & - & - & - & $.18 \pm .06$ & $.26 \pm .05$ \\
\hline p-value & - & - & - & $p=0.0034$ & $\mathrm{p}<0.0001$ \\
\hline \multicolumn{6}{|l|}{$\begin{array}{l}\text { Estimated Mean } \\
\text { SRKN count } \\
\text { (95\% Confidence } \\
\text { Limits) } \\
\end{array}$} \\
\hline $\mathrm{PNS}=0$ & $\begin{array}{c}1.80 \\
(1.52,2.14)\end{array}$ & $\begin{array}{c}1.80 \\
(1.40,2.32)\end{array}$ & $\begin{array}{c}1.81 \\
(1.40,2.33)\end{array}$ & $\begin{array}{c}1.83 \\
(1.46,2.20) \\
\end{array}$ & $\begin{array}{c}1.66 \\
(1.26,2.06)\end{array}$ \\
\hline $\mathrm{PNS}=1$ & $\begin{array}{c}3.00 \\
(2.38,3.78)\end{array}$ & $\begin{array}{c}3.00 \\
(2.14,4.21)\end{array}$ & $\begin{array}{c}2.99 \\
(2.12,4.21)\end{array}$ & $\begin{array}{c}2.77 \\
(2.05,3.50)\end{array}$ & $\begin{array}{c}2.49 \\
(1.80,3.18)\end{array}$ \\
\hline $\mathrm{PNS}=2$ & $\begin{array}{c}5.00 \\
(3.20,7.80) \\
\end{array}$ & $\begin{array}{c}5.00 \\
(2.60,9.59) \\
\end{array}$ & $\begin{array}{c}4.96 \\
(2.58,9.54) \\
\end{array}$ & $\begin{array}{c}4.21 \\
(2.20,6.21) \\
\end{array}$ & $\begin{array}{c}3.73 \\
(1.93,5.53)\end{array}$ \\
\hline $\mathrm{PNS}=3$ & $\begin{array}{c}8.32 \\
(4.21,16.45)\end{array}$ & $\begin{array}{c}8.32 \\
(3.07,22.55)\end{array}$ & $\begin{array}{c}8.22 \\
(3.03,22.30)\end{array}$ & $\begin{array}{c}6.38 \\
(1.78,10.97)\end{array}$ & $\begin{array}{c}5.59 \\
(1.55,9.63)\end{array}$ \\
\hline $\mathrm{PNS}=4$ & $\begin{array}{c}13.86 \\
(5.51,34.85) \\
\end{array}$ & $\begin{array}{c}13.86 \\
(3.59,53.43) \\
\end{array}$ & $\begin{array}{c}13.61 \\
(3.52,52.56) \\
\end{array}$ & $\begin{array}{c}9.66 \\
(.27,19.06) \\
\end{array}$ & $\begin{array}{c}8.38 \\
(.21,16.55) \\
\end{array}$ \\
\hline
\end{tabular}

${ }^{\mathrm{a}}$ Analyses performed using SAS ${ }^{\circledR}$ procedures: GENMOD (Poisson, Poisson with Dscale option, Zero-Inflated Poisson); GLIMMIX (Poisson, Generalized Poisson); and NLMIXED (Zero-inflated Poisson, Poisson Hurdle). ${ }^{\mathrm{b}}$ s.e. =standard error. Standard errors were not calculated in SAS procedures for all estimates. In those cases only the point estimate is given.

${ }^{\mathrm{c}}$ - indicates that the specific result was not applicable to, or calculated for, that probability model. 
Table 3. Results for September 2006 data for Southern root knot nematode (SRKN) J2 counts (response) as a function of the predictor purple nutsedge counts (P) using the probability models: Poisson ${ }^{\mathrm{a}}$, Poisson with Dscale correction, Generalized Poisson, Zero-Inflated Poisson and Poisson Hurdle ( $\mathrm{n}=80$ ).

\begin{tabular}{|c|c|c|c|c|c|}
\hline Results & Poisson & $\begin{array}{c}\text { Poisson with } \\
\text { Dscale }\end{array}$ & $\begin{array}{c}\text { Generalized } \\
\text { Poisson } \\
\end{array}$ & $\begin{array}{l}\text { Zero-Inflated } \\
\text { Poisson }\end{array}$ & $\begin{array}{l}\text { Poisson } \\
\text { Hurdle } \\
\end{array}$ \\
\hline Pearson's $\chi^{2}$ & 140.1 & 140.1 & 68.3 & 84.0 & - \\
\hline d.f. & 78 & 78 & 80 & 77 & - \\
\hline$\chi^{2} / d . f$. & 1.80 & 1.80 & .85 & 1.09 & - \\
\hline AIC & 141.6 & 141.6 & 130.8 & 131.7 & 132.8 \\
\hline \multicolumn{6}{|l|}{$\begin{array}{l}\text { Poisson Mu } \\
\text { Model Beta } \\
\text { Estimates } \pm \text { s.e. }\end{array}$} \\
\hline$\hat{\beta}_{0} \pm$ s.e. & $-1.26 \pm .23$ & $-1.26 \pm .26$ & $-1.28 \pm .32$ & $-.08 \pm .36$ & $.07 \pm .34$ \\
\hline $\mathrm{p}$-value & $\mathrm{p}<0.0001$ & $\mathrm{p}<0.0001$ & $\mathrm{p}=0.0002$ & $\mathrm{p}=0.8186$ & $\mathrm{p}=0.8372$ \\
\hline$\hat{\beta}_{P} \pm$ s.e. & $.26 \pm .10$ & $.26 \pm .10$ & $.27 \pm .12$ & $.13 \pm .10$ & $.07 \pm .12$ \\
\hline $\mathrm{p}$-value & $p=0.0059$ & $\mathrm{p}=0.0125$ & $\mathrm{p}=0.0285$ & $p=0.2014$ & $\mathrm{p}=0.5554$ \\
\hline \multicolumn{6}{|l|}{ Scale Estimate } \\
\hline$\hat{\phi} \pm$ s.e. & $-{ }^{\mathrm{C}}$ & 1.01 & $.36 \pm .17$ & - & - \\
\hline$\hat{\xi}=1-1 / \exp (\hat{\phi})$ & - & - & .30 & - & - \\
\hline \multicolumn{6}{|l|}{$\begin{array}{l}\text { Inflation } \\
\text { Parameter } \\
\text { Estimates }\end{array}$} \\
\hline$\hat{\alpha}_{0} \pm$ s.e. & - & - & - & $.61 \pm .42$ & $1.24 \pm .27$ \\
\hline p-value & - & - & - & $p=0.1439$ & $\mathrm{p}<0.0001$ \\
\hline$\hat{\pi} \pm$ s.e. & - & - & - & $.65 \pm .10$ & $.78 \pm .05$ \\
\hline p-value & - & - & - & $\mathrm{p}<0.0001$ & $\mathrm{p}<0.0001$ \\
\hline \multicolumn{6}{|l|}{$\begin{array}{l}\text { Estimated Mean } \\
\text { SRKN count } \\
\text { (95\% Confidence } \\
\text { Limits) } \\
\end{array}$} \\
\hline $\mathrm{PNS}=0$ & $\begin{array}{c}.28 \\
(.18, .45)\end{array}$ & $\begin{array}{c}.28 \\
(.17, .47) \\
\end{array}$ & $\begin{array}{c}.28 \\
(.15, .53)\end{array}$ & $\begin{array}{c}.32 \\
(.14, .50) \\
\end{array}$ & $\begin{array}{c}.24 \\
(.05, .43)\end{array}$ \\
\hline $\mathrm{PNS}=1$ & $\begin{array}{c}.37 \\
(.25, .53)\end{array}$ & $\begin{array}{c}.37 \\
(.24, .55)\end{array}$ & $\begin{array}{c}.37 \\
(.21, .62)\end{array}$ & $\begin{array}{c}.37 \\
(.19, .55)\end{array}$ & $\begin{array}{c}.26 \\
(.08, .44)\end{array}$ \\
\hline $\mathrm{PNS}=2$ & $\begin{array}{c}.48 \\
(.33, .68)\end{array}$ & $\begin{array}{c}.48 \\
(.32, .71)\end{array}$ & $\begin{array}{c}.48 \\
(.28, .81) \\
\end{array}$ & $\begin{array}{c}.42 \\
(.22, .63)\end{array}$ & $\begin{array}{c}.28 \\
(.09, .46) \\
\end{array}$ \\
\hline $\mathrm{PNS}=3$ & $\begin{array}{c}.62 \\
(.40, .96)\end{array}$ & $\begin{array}{c}.62 \\
(.38,1.01)\end{array}$ & $\begin{array}{c}.63 \\
(.34,1.16)\end{array}$ & $\begin{array}{c}.48 \\
(.21, .76)\end{array}$ & $\begin{array}{c}.30 \\
(.08, .52)\end{array}$ \\
\hline $\mathrm{PNS}=4$ & $\begin{array}{c}.80 \\
(.45,1.43) \\
\end{array}$ & $\begin{array}{c}.80 \\
(.43,1.51) \\
\end{array}$ & $\begin{array}{c}.82 \\
(.38,1.77) \\
\end{array}$ & $\begin{array}{c}.55 \\
(.16, .94) \\
\end{array}$ & $\begin{array}{c}.32 \\
(.05, .60) \\
\end{array}$ \\
\hline
\end{tabular}

${ }^{\mathrm{a}}$ Analyses performed using SAS ${ }^{\circledR}$ procedures: GENMOD (Poisson, Poisson with Dscale, Zero-Inflated Poisson); GLIMMIX ( Poisson, Generalized Poisson); and NLMIXED (Zero-Inflated Poisson, Poisson Hurdle).

${ }^{\mathrm{b}}$ s.e. =standard error. Standard errors were not calculated in SAS procedures for all estimates. In those cases only the point estimate is given.

${ }^{\mathrm{c}}$ - indicates that the specific result was not applicable to, or calculated for, that probability model. 
Table 4. Results for July 2005 data for Southern root knot nematode (SRKN) J2 counts (response) as a function of predictors yellow nutsedge $(\mathrm{Y})$, purple nutsedge counts $(\mathrm{P})$ and their cross-product (YP) using the probability models: Poisson ${ }^{\mathrm{a}}$, Poisson with Dscale correction, Generalized Poisson, ZeroInflated Poisson and Poisson Hurdle $(\mathrm{n}=80)$.

\begin{tabular}{|c|c|c|c|c|c|}
\hline Results & Poisson & $\begin{array}{l}\text { Poisson with } \\
\text { Dscale }\end{array}$ & $\begin{array}{l}\text { Generalized } \\
\text { Poisson }\end{array}$ & $\begin{array}{l}\text { Zero-Inflated } \\
\text { Poisson }\end{array}$ & $\begin{array}{l}\text { Poisson } \\
\text { Hurdle }\end{array}$ \\
\hline Pearson's $\chi^{2}$ & 107.7 & 107.7 & 76.3 & 84.2 & - \\
\hline d.f. & 76 & 76 & 80 & 75 & - \\
\hline$\chi^{2} / d . f$. & 1.42 & 1.42 & .95 & 1.12 & - \\
\hline$\overline{A I C}$ & 219.3 & 219.3 & 217.1 & 215.6 & 218.5 \\
\hline \multicolumn{6}{|c|}{$\begin{array}{l}\text { Poisson Mu } \\
\text { Model Beta } \\
\text { Estimates } \pm \text { s.e. }^{\text {b }} \\
\end{array}$} \\
\hline$\hat{\beta}_{0} \pm$ s.e. & $-.63 \pm .23$ & $-.63 \pm .28$ & $-.63 \pm .27$ & $-.42 \pm .32$ & $-.23 \pm .38$ \\
\hline $\mathrm{p}$-value & $\mathrm{p}=0.0065$ & $\mathrm{p}=0.0250$ & $\mathrm{p}=0.0226$ & $\mathrm{p}=0.1870$ & $\mathrm{p}=0.5420$ \\
\hline$\hat{\beta}_{Y} \pm$ s.e. & $.09 \pm .03$ & $.09 \pm .04$ & $.09 \pm .03$ & $.09 \pm .03$ & $.06 \pm .04$ \\
\hline $\mathrm{p}$-value & $\mathrm{p}=0.0023$ & $\mathrm{p}=0.0120$ & $\mathrm{p}=0.0091$ & $\mathrm{p}=0.0087$ & $\mathrm{p}=0.1235$ \\
\hline$\hat{\beta}_{P} \pm$ s.e. & $.13 \pm .06$ & $.13 \pm .07$ & $.13 \pm .07$ & $.18 \pm .11$ & $.08 \pm .13$ \\
\hline $\mathrm{p}$-value & $\mathrm{p}=0.0401$ & $\mathrm{p}=0.0911$ & $\mathrm{p}=0.0726$ & $\mathrm{p}=0.0931$ & $\mathrm{p}=0.5602$ \\
\hline$\hat{\beta}_{Y P} \pm$ s.e. & $-.01 \pm .01$ & $-.01 \pm .01$ & $-.02 \pm .01$ & $-.02 \pm .01$ & $-.002 \pm .02$ \\
\hline p-value & $\mathrm{p}=0.0852$ & $p=0.1565$ & $\mathrm{p}=0.1141$ & $\mathrm{p}=0.1876$ & $\mathrm{p}=0.9145$ \\
\hline \multicolumn{6}{|l|}{ Scale Estimate } \\
\hline$\hat{\phi} \pm$ s.e. & - & 1.21 & $.17 \pm .10$ & - & - \\
\hline$\hat{\xi}=1-1 / \exp (\hat{\phi})$ & - & - & .16 & - & - \\
\hline \multicolumn{6}{|l|}{$\begin{array}{l}\text { Inflation } \\
\text { Parameter } \\
\text { Estimates } \\
\end{array}$} \\
\hline$\hat{\alpha}_{0} \pm$ s.e. & - & - & - & $-1.13 \pm .53$ & $-.05 \pm .22$ \\
\hline p-value & - & - & - & $\mathrm{p}=0.0355$ & $\mathrm{p}=0.8237$ \\
\hline$\hat{\pi} \pm$ s.e. & - & - & - & $.24 \pm .10$ & $.49 \pm .06$ \\
\hline p-value & - & - & - & $p=0.0325$ & $\mathrm{p}<0.0001$ \\
\hline
\end{tabular}

${ }^{\mathrm{a}}$ Analyses performed using SAS ${ }^{\circledR}$ procedures: GENMOD (Poisson, Poisson with Dscale, Zero-Inflated Poisson); GLIMMIX ( Poisson, Generalized Poisson); and NLMIXED (Zero-Inflated Poisson, Poisson Hurdle).

${ }^{b}$ s.e. =standard error. Standard errors were not calculated in SAS procedures for all estimates. In those cases only the point estimate is given.

${ }^{\mathrm{c}}$ - indicates that the specific result was not applicable to, or calculated for, that probability model. 
Table 5. Results for September 2005 data for Southern root knot nematode (SRKN) J2 counts (response) as a function of predictors yellow nutsedge (Y), purple nutsedge counts (P) and their cross-product (YP) using the probability models: Poisson ${ }^{\mathrm{a}}$, Poisson with Dscale correction, Generalized Poisson, ZeroInflated Poisson and Poisson Hurdle ( $\mathrm{n}=80)$.

\begin{tabular}{|c|c|c|c|c|c|}
\hline Results & Poisson & $\begin{array}{c}\text { Poisson with } \\
\text { Dscale }\end{array}$ & $\begin{array}{c}\text { Generalized } \\
\text { Poisson } \\
\end{array}$ & $\begin{array}{l}\text { Zero-Inflated } \\
\text { Poisson }\end{array}$ & $\begin{array}{l}\text { Poisson } \\
\text { Hurdle }\end{array}$ \\
\hline Pearson's $\chi^{2}$ & 152.7 & 152.7 & 100.8 & 77.6 & - \\
\hline d.f. & 75 & 75 & 80 & 75 & - \\
\hline$\chi^{2} / d . f$. & 2.01 & 2.01 & 1.26 & 1.03 & - \\
\hline AIC & 213.9 & 213.9 & 198.5 & 194.5 & 180.9 \\
\hline \multicolumn{6}{|c|}{$\begin{array}{l}\text { Poisson Mu } \\
\text { Model Beta } \\
\text { Estimates } \pm \text { s.e. } \\
\end{array}$} \\
\hline$\hat{\beta}_{0} \pm$ s.e. & $-.79 \pm .24$ & $-.79 \pm .30$ & $-.53 \pm .31$ & $-.44 \pm .31$ & $-.97 \pm .48$ \\
\hline p-value & $p=0.0020$ & $p=0.0166$ & $p=0.0960$ & $p=0.1605$ & $p=0.0462$ \\
\hline$\hat{\beta}_{Y} \pm$ s.e. & $.39 \pm .15$ & $.39 \pm .20$ & $.04 \pm .27$ & $1.05 \pm .23$ & $1.56 \pm .29$ \\
\hline $\mathrm{p}$-value & $\mathrm{p}=0.0112$ & $p=0.0494$ & $p=0.8848$ & $\mathrm{p}<0.0001$ & $p<0.0001$ \\
\hline$\hat{\beta}_{P} \pm$ s.e. & $.16 \pm .07$ & $.16 \pm .09$ & $.10 \pm .11$ & $.22 \pm .08$ & $.31 \pm .11$ \\
\hline $\mathrm{p}$-value & $\mathrm{p}=0.0279$ & $\mathrm{p}=0.0885$ & $\mathrm{p}=.3401$ & $\mathrm{p}=0.0098$ & $\mathrm{p}=.0044$ \\
\hline$\hat{\beta}_{Y P} \pm$ s.e. & $-.12 \pm .06$ & $-.12 \pm .07$ & $-.006 \pm .08$ & $-.31 \pm .08$ & $-.56 \pm .12$ \\
\hline p-value & $\mathrm{p}=0.0383$ & $p=0.1085$ & $p=0.9448$ & $\mathrm{p}<0.0001$ & $\mathrm{p}<0.0001$ \\
\hline \multicolumn{6}{|l|}{ Scale Estimate } \\
\hline$\hat{\phi} \pm$ s.e. & - & 1.29 & $.34 \pm .12$ & - & - \\
\hline$\hat{\xi}=1-1 / \exp (\hat{\phi})$ & - & - & .29 & - & - \\
\hline \multicolumn{6}{|l|}{$\begin{array}{l}\text { Inflation } \\
\text { Parameter } \\
\text { Estimates } \\
\end{array}$} \\
\hline$\hat{\alpha}_{0} \pm$ s.e. & - & - & - & $-.37 \pm .35$ & $.30 \pm .23$ \\
\hline p-value & - & - & - & $\mathrm{p}=0.2892$ & $\mathrm{p}=0.1852$ \\
\hline$\hat{\pi} \pm$ s.e. & - & - & - & $.41 \pm .08$ & $.58 \pm .06$ \\
\hline p-value & - & - & - & $\mathrm{p}<0.0001$ & $\mathrm{p}<0.0001$ \\
\hline
\end{tabular}

${ }^{\mathrm{a}}$ Analyses performed using SAS ${ }^{\circledR}$ procedures: GENMOD (Poisson, Poisson with Dscale, Zero-Inflated Poisson); GLIMMIX ( Poisson, Generalized Poisson); and NLMIXED (Zero-Inflated Poisson, Poisson Hurdle).

${ }^{\mathrm{b}}$ s.e. =standard error. Standard errors were not calculated in SAS procedures for all estimates. In those cases only the point estimate is given.

${ }^{\mathrm{c}}$ - indicates that the specific result was not applicable to, or calculated for, that probability model. 
Table 6. Results for May 2006 data for an intercept-only model Southern root knot nematode (SRKN) J2 counts (response) using the probability models: Poisson ${ }^{a}$, Poisson with Dscale correction, Generalized Poisson, Zero-Inflated Poisson and Poisson Hurdle $(n=80)$.

\begin{tabular}{|c|c|c|c|c|c|}
\hline Results & Poisson & $\begin{array}{l}\text { Poisson with } \\
\text { Dscale }\end{array}$ & $\begin{array}{l}\text { Generalized } \\
\text { Poisson }\end{array}$ & $\begin{array}{l}\text { Zero-Inflated } \\
\text { Poisson }\end{array}$ & $\begin{array}{l}\text { Poisson } \\
\text { Hurdle }\end{array}$ \\
\hline Pearson's $\chi^{2}$ & 156.4 & 156.4 & 79.5 & 100.2 & - \\
\hline d.f. & 79 & 79 & 80 & 78 & - \\
\hline$\chi^{2} / d . f$. & 1.98 & 1.98 & .99 & 1.28 & - \\
\hline AIC & 198.6 & 198.6 & 184.1 & 189.5 & 189.5 \\
\hline \multicolumn{6}{|l|}{$\begin{array}{l}\text { Poisson Mu } \\
\text { Model Beta } \\
\text { Estimates } \pm \text { s.e. }^{\text {b }} \\
\end{array}$} \\
\hline$\hat{\beta}_{0} \pm$ s.e. & $-.39 \pm .14$ & $-.39 \pm .17$ & $-.39 \pm .19$ & $.21 \pm .19$ & $.21 \pm .19$ \\
\hline p-value & $\mathrm{p}=0.0039$ & $\mathrm{p}=0.0212$ & $\mathrm{p}=0.0427$ & $\mathrm{p}=0.2746$ & $\mathrm{p}=0.2779$ \\
\hline \multicolumn{6}{|l|}{ Scale Estimate } \\
\hline$\hat{\phi} \pm$ s.e. & $-{ }^{\mathrm{C}}$ & 1.25 & $.34 \pm .13$ & - & - \\
\hline$\hat{\xi}=1-1 / \exp (\hat{\phi})$ & - & - & .29 & - & - \\
\hline \multicolumn{6}{|l|}{$\begin{array}{l}\text { Inflation } \\
\text { Parameter } \\
\text { Estimates } \\
\end{array}$} \\
\hline$\hat{\alpha}_{0} \pm$ s.e. & - & - & - & $-.19 \pm .38$ & $.46 \pm .05$ \\
\hline p-value & - & - & - & $\mathrm{p}=0.6231$ & $\mathrm{p}=0.0494$ \\
\hline$\hat{\pi} \pm$ s.e. & - & - & - & $.45 \pm .38$ & $.61 \pm .05$ \\
\hline p-value & - & - & - & $\mathrm{p}<0.0001$ & $\mathrm{p}<0.0001$ \\
\hline \multicolumn{6}{|l|}{$\begin{array}{l}\text { Estimated Mean } \\
\text { SRKN count } \\
\text { (95\% Confidence } \\
\text { Limits) }\end{array}$} \\
\hline $\begin{array}{l}\text { Any value of PNS } \\
\text { or YNS }\end{array}$ & $\begin{array}{c}.68 \\
(.52, .88)\end{array}$ & $\begin{array}{c}.68 \\
(.48, .94)\end{array}$ & $\begin{array}{c}.68 \\
(.46, .99)\end{array}$ & $\begin{array}{c}.68 \\
(.45, .90)\end{array}$ & $\begin{array}{c}.48 \\
(.25, .71)\end{array}$ \\
\hline
\end{tabular}

${ }^{\mathrm{a}}$ Analyses performed using SAS ${ }^{\circledR}$ procedures: GENMOD (Poisson, Poisson with Dscale option, Zero-Inflated Poisson); GLIMMIX (Poisson, Generalized Poisson); and NLMIXED (Zero-inflated Poisson, Poisson Hurdle).

${ }^{\mathrm{b}}$ s.e. =standard error. Standard errors were not calculated in SAS procedures for all estimates. In those cases only the point estimate is given.

${ }^{\mathrm{c}}$ - indicates that the specific result was not applicable to, or calculated for, that probability model. 
Table 7. Results for July 2006 data for an intercept-only model Southern root knot nematode (SRKN) J2 counts (response) using the probability models: Poisson ${ }^{a}$, Poisson with Dscale correction, Generalized Poisson, Zero-Inflated Poisson and Poisson Hurdle $(n=80)$.

\begin{tabular}{|c|c|c|c|c|c|}
\hline Results & Poisson & $\begin{array}{c}\text { Poisson with } \\
\text { Dscale }\end{array}$ & $\begin{array}{c}\text { Generalized } \\
\text { Poisson }\end{array}$ & $\begin{array}{l}\text { Zero-Inflated } \\
\text { Poisson }\end{array}$ & $\begin{array}{l}\text { Poisson } \\
\text { Hurdle }\end{array}$ \\
\hline Pearson's $\chi^{2}$ & 116.0 & 116.0 & 81.96 & 91.2 & - \\
\hline d.f. & 79 & 79 & 80 & 78 & - \\
\hline$\chi^{2} / d . f$. & 1.47 & 1.47 & 1.02 & 1.17 & - \\
\hline AIC & 167.7 & 167.7 & 165.0 & 166.7 & 166.7 \\
\hline \multicolumn{6}{|l|}{$\begin{array}{l}\text { Poisson Mu } \\
\text { Model Beta } \\
\text { Estimates } \pm \text { s.e. }^{\text {b }} \\
\end{array}$} \\
\hline$\hat{\beta}_{0} \pm$ s.e. & $-.60 \pm .15$ & $-.60 \pm .17$ & $-.60 \pm .18$ & $-.20 \pm .25$ & $-.19 \pm .25$ \\
\hline p-value & $\mathrm{p}<0.0001$ & $p=0.0004$ & $\mathrm{p}=0.0013$ & $\mathrm{p}=0.4382$ & $p=0.4405$ \\
\hline \multicolumn{6}{|l|}{ Scale Estimate } \\
\hline$\hat{\phi} \pm s . e$. & $-{ }^{c}$ & 1.12 & $.17 \pm .10$ & - & - \\
\hline$\hat{\xi}=1-1 / \exp (\hat{\phi})$ & - & - & & - & - \\
\hline \multicolumn{6}{|l|}{$\begin{array}{l}\text { Inflation } \\
\text { Parameter } \\
\text { Estimates } \\
\end{array}$} \\
\hline$\hat{\alpha}_{0} \pm$ s.e. & - & - & - & $-.70 \pm .66$ & $.51 \pm .23$ \\
\hline p-value & - & - & - & $\mathrm{p}=.2846$ & $\mathrm{p}=0.0298$ \\
\hline$\hat{\pi} \pm$ s.e. & - & - & - & $.33 \pm .15$ & $.63 \pm .05$ \\
\hline p-value & - & - & - & $\mathrm{p}=0.0258$ & $\mathrm{p}<0.0001$ \\
\hline \multicolumn{6}{|l|}{$\begin{array}{l}\text { Estimated Mean } \\
\text { SRKN count } \\
\text { (95\% Confidence } \\
\text { Limits) }\end{array}$} \\
\hline $\begin{array}{l}\text { Any value of PNS } \\
\text { or YNS }\end{array}$ & $\begin{array}{c}.55 \\
(.41, .74)\end{array}$ & $\begin{array}{c}.55 \\
(.40, .77)\end{array}$ & $\begin{array}{c}.55 \\
(.38, .79)\end{array}$ & $\begin{array}{c}.55 \\
(.36, .74)\end{array}$ & $\begin{array}{c}.31 \\
(.13, .49)\end{array}$ \\
\hline
\end{tabular}

${ }^{\mathrm{a}}$ Analyses performed using SAS ${ }^{\circledR}$ procedures: GENMOD (Poisson, Poisson with Dscale option, Zero-Inflated Poisson); GLIMMIX (Poisson, Generalized Poisson); and NLMIXED (Zero-inflated Poisson, Poisson Hurdle). ${ }^{\mathrm{b}}$ s.e. $=$ standard error. Standard errors were not calculated in SAS procedures for all estimates. In those cases only the point estimate is given.

${ }^{\mathrm{c}}$ - indicates that the specific result was not applicable to, or calculated for, that probability model. 


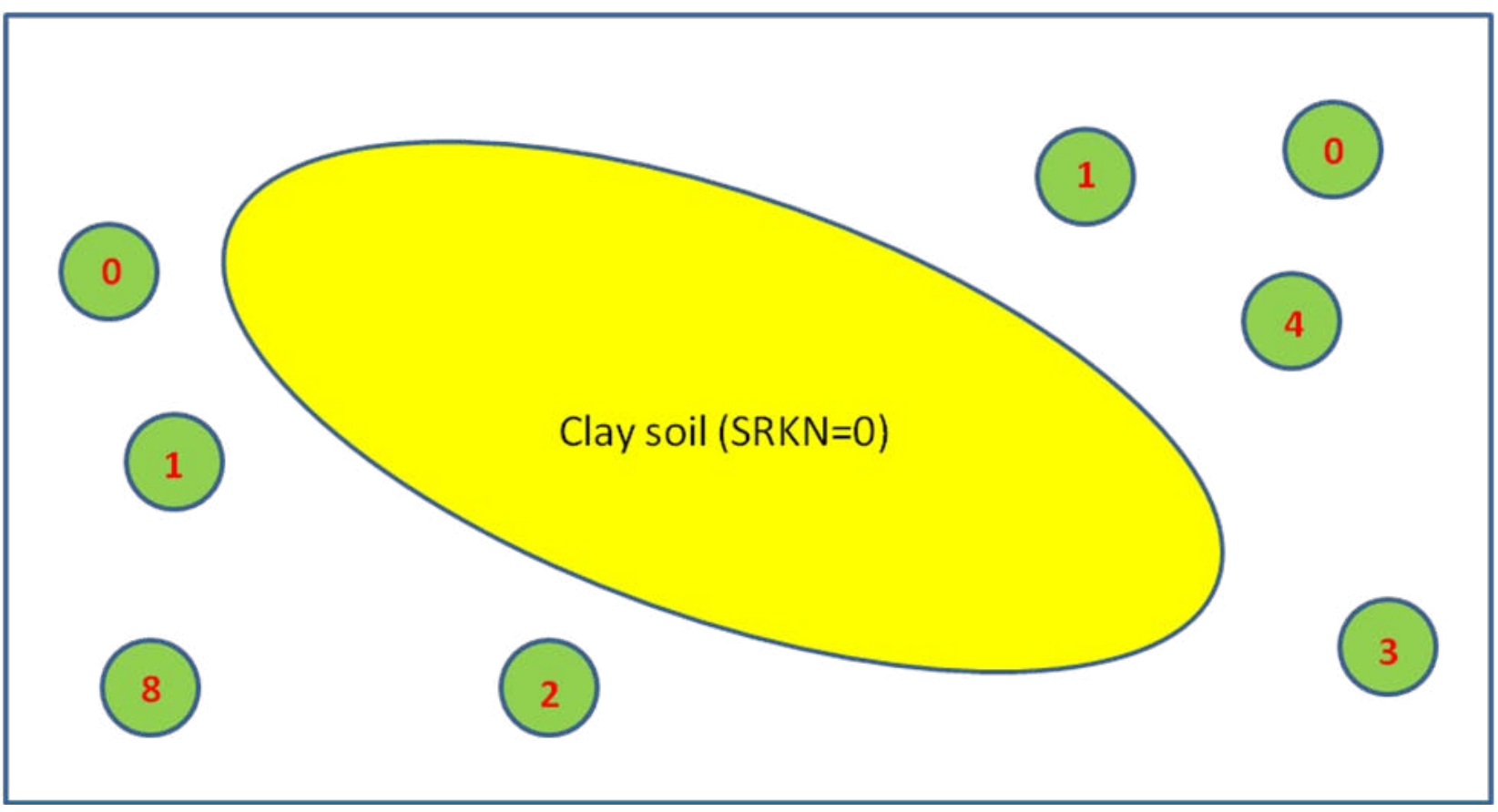

Figure 1. Biological field scenario that may be represented by the Zero-Inflated Poisson model. Field conditions: mostly sandy soil with a clay region where SRKN does not occur and the crop is a non-host for SRKN; all weeds are hosts and occur in patches (green circles); the number inside each circle represents the SRKN count associated with that host.

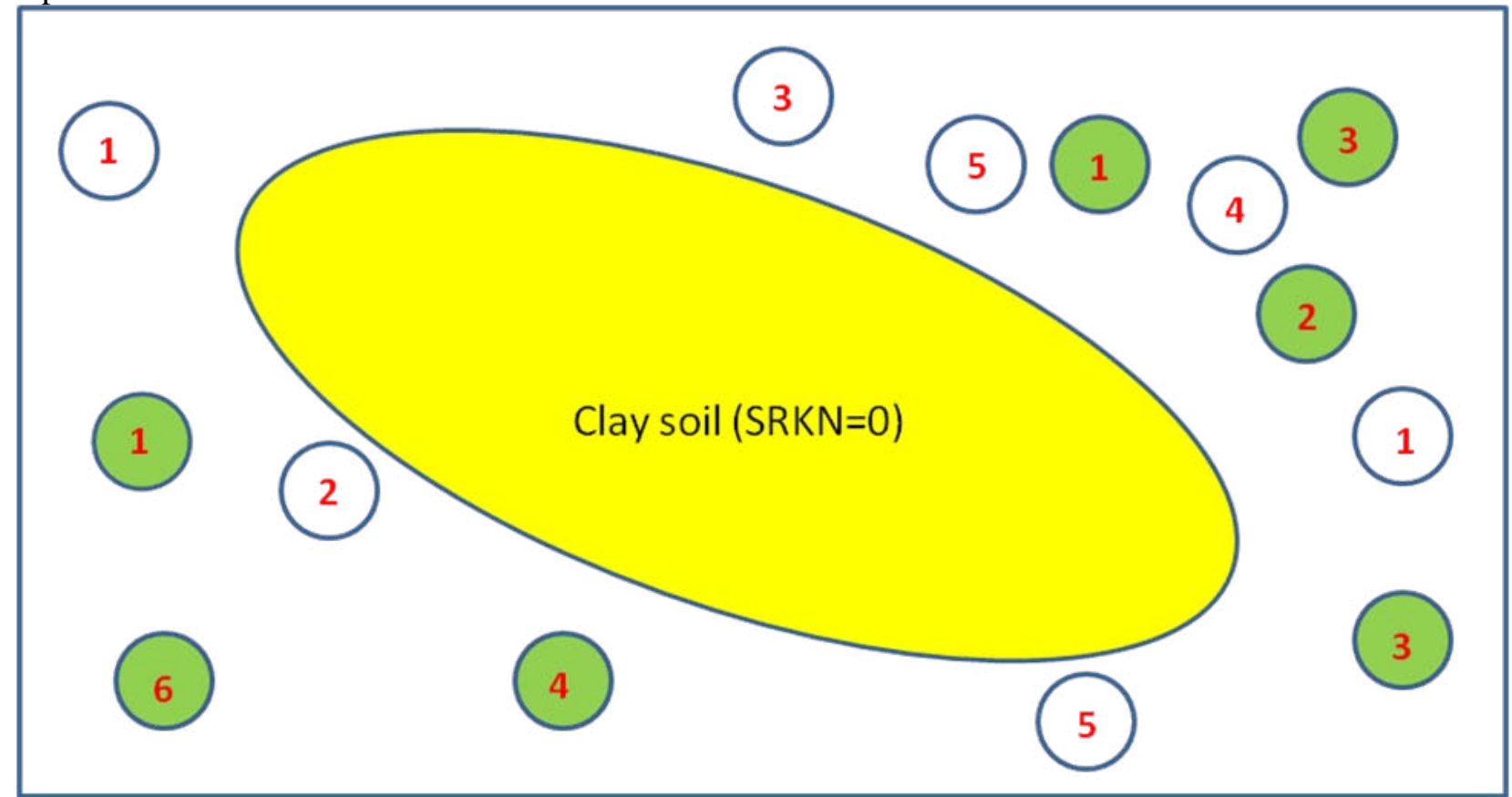

Figure 2. Biological field scenario that may be represented by the Poisson Hurdle model. Field conditions: mostly sandy soil with clay region where SRKN does not occur; the crop is a host (open circles); all weeds are hosts and occur in patches (green circles); the number inside each circle represents the SRKN count associated with that host. 


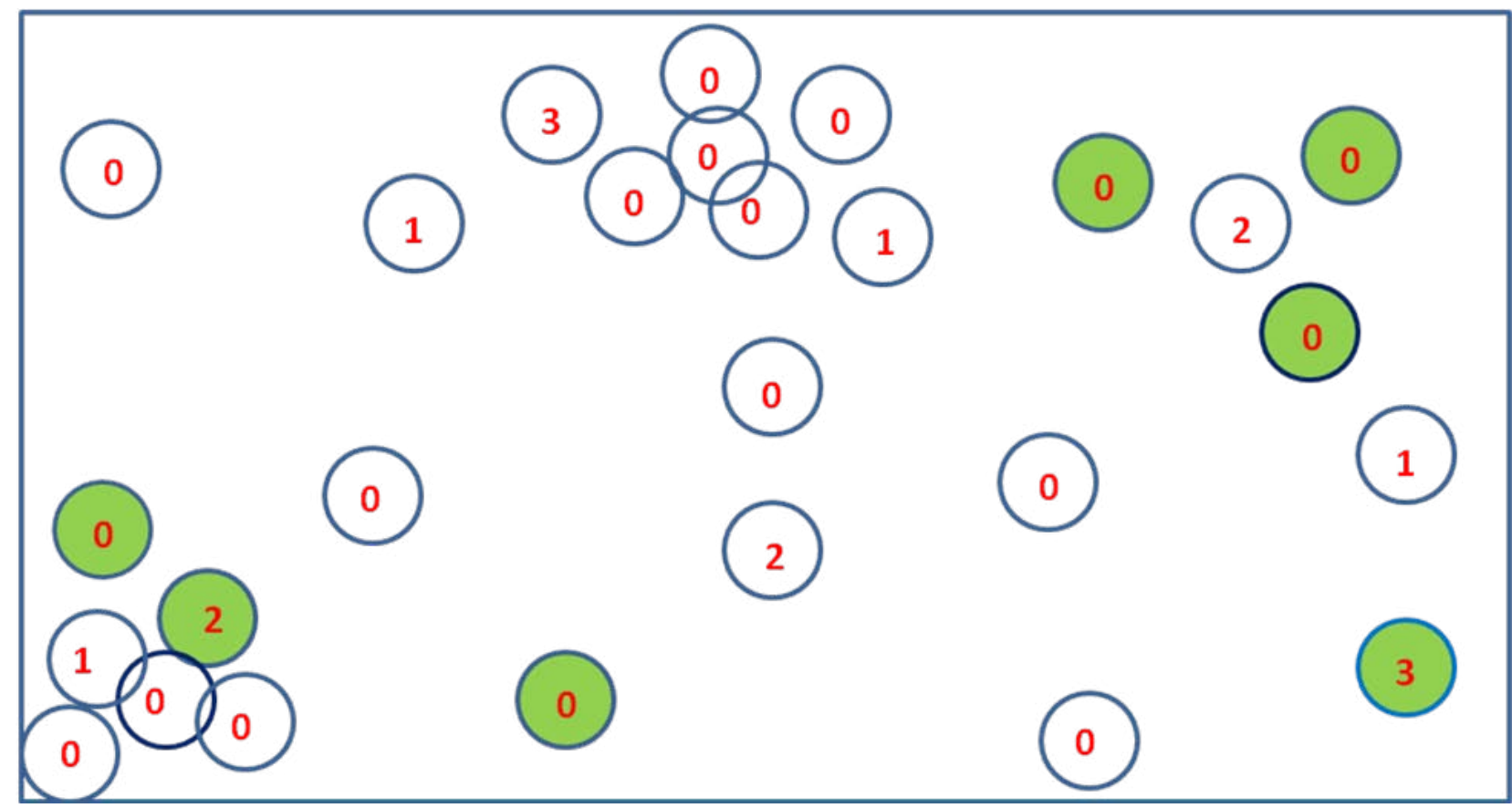

Figure 3. Biological field scenario that may be represented by the Poisson model. Field conditions: sandy soil with flood or center-pivot irrigation and where SRKN is at low levels due to a recent introduction; the crop is a host (open circles); weeds are all hosts and occur in patches (green circles); the number inside each circle represents the SRKN count associated with that host.

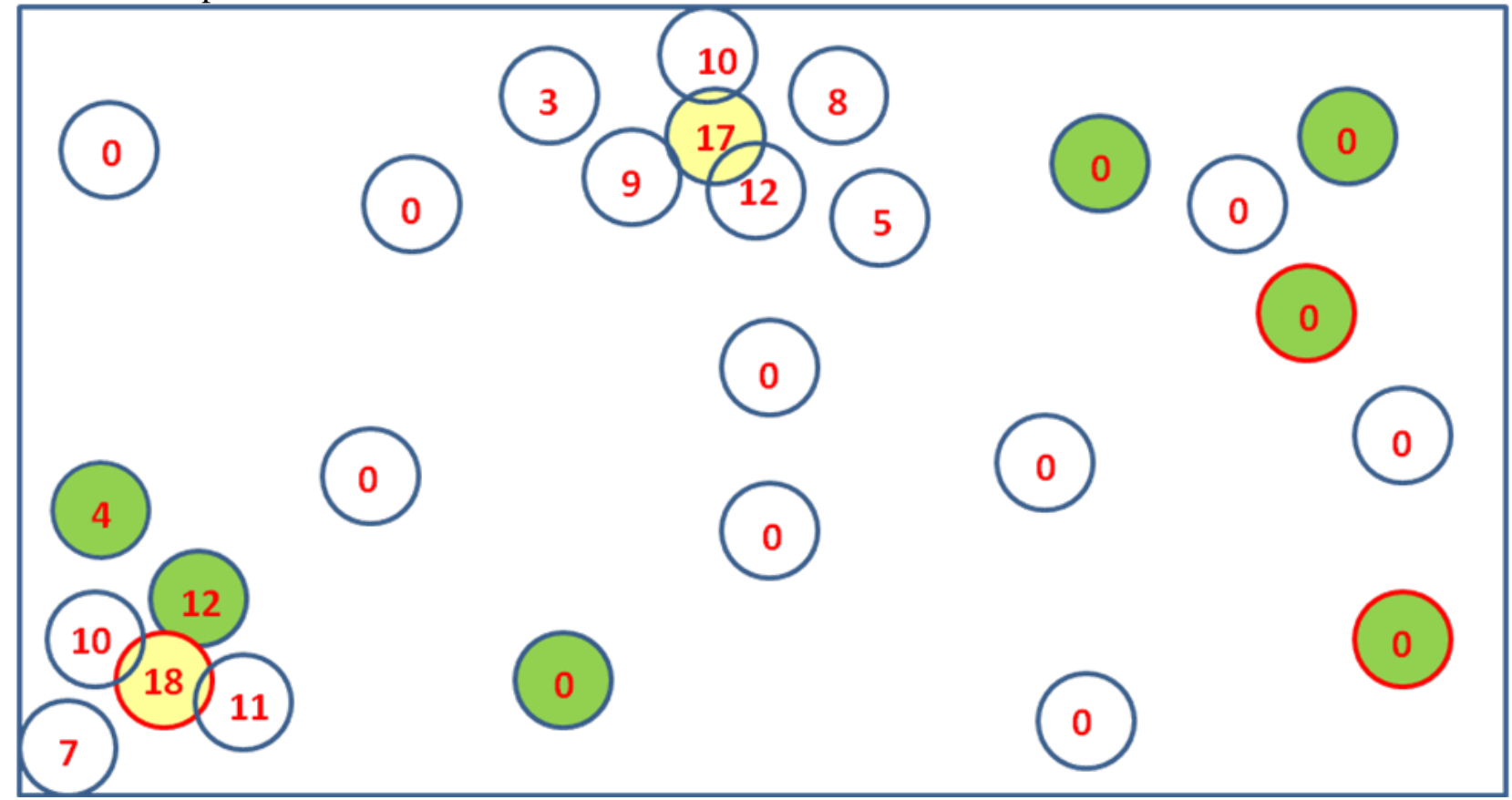

Figure 4. Biological field scenario that may be represented by the Generalized Poisson model. Field conditions: sandy soil with center-pivot irrigation and where SRKN is present in 'hot spots' (yellow circles); the crop is a host (open circles); weeds are all hosts and occur in patches (green circles); the number inside each circle represents the SRKN count associated with that host. 


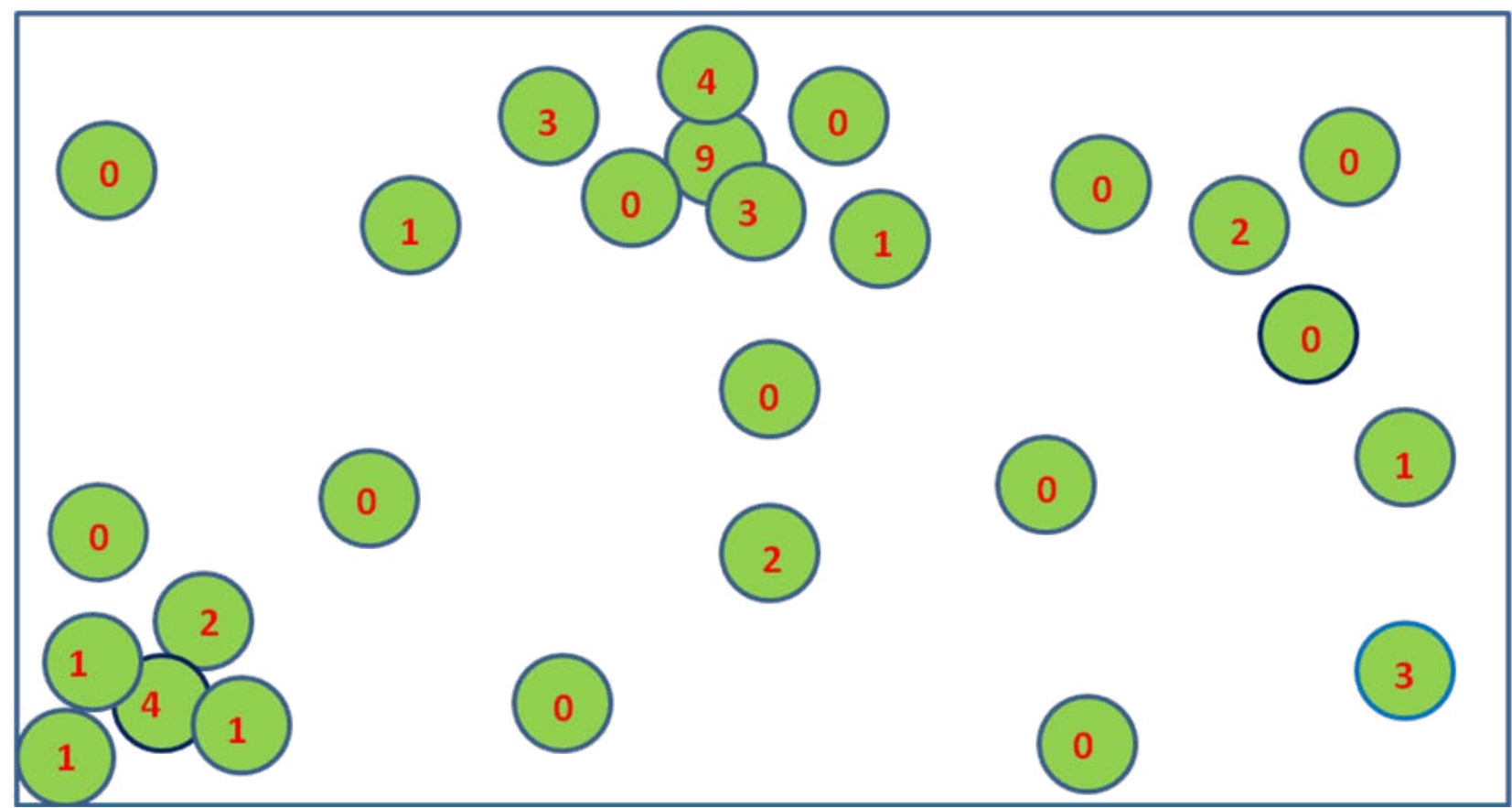

Figure 5. Illustration of nutsedge and SRKN distribution for the study site in May 2005. Field conditions: sandy soil with flood irrigation and well established populations of SRKN and nutsedge; the crop is recently planted non-host alfalfa; weeds are all hosts and occur in dense patches (green circles); the number inside each circle represents the SRKN count associated with that host.

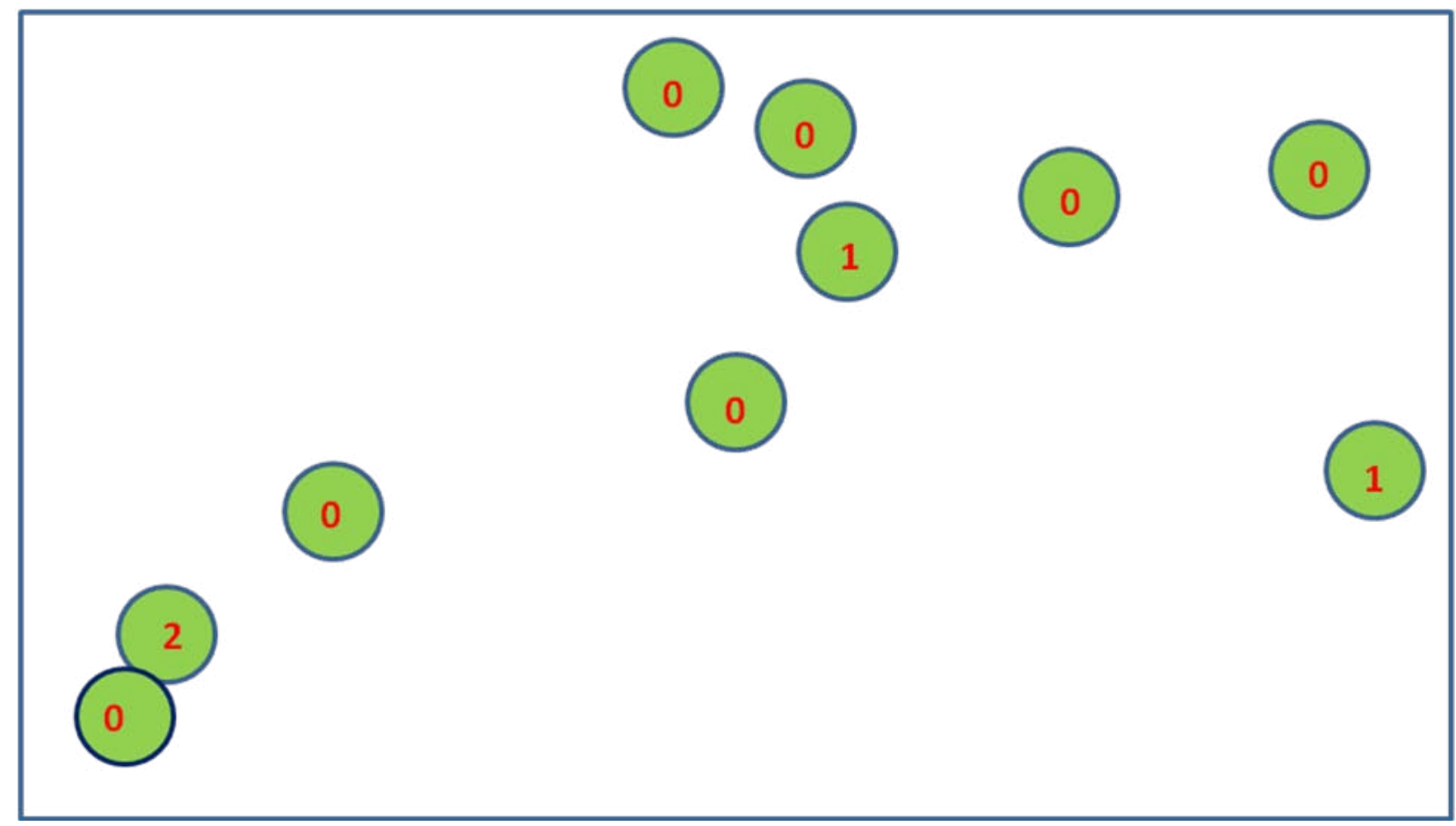

Figure 6. Illustration of nutsedge and SRKN distribution for the study site in September 2006. Field conditions: sandy soil with flood irrigation and suppressed populations of SRKN and nutsedge; the non-host alfalfa crop has been established for 2 years; weeds are all hosts and are widely dispersed, small patches (green circles); the number inside each circle represents the SRKN count associated with that host. 